\section{UNIVERSITY AND EDUCATIONAL NEWS}

A contribution of $\$ 50,000$ from Mrs. E. H. Harriman to the endowment fund of Barnard College, Columbia University, is announced toward the million dollar fund now being raised for the twenty-fifth anniversary of the institution $\$ 550,000$ is now pledged.

Dr. J. B. Johnston, professor of neurology in the department of anatomy of the University of Minnesota, has been appointed professor in the department of animal biology in the College of Science, Literature and the Arts, and dean of that college from August 1, 1914.

Richard Laban Adams, a graduate of Massachusetts Agricultural College and M.S. of the University of California, has been appointed assistant professor of agronomy in the University of California. James Alexander Armstrong, a graduate of 1910 of the University of California, and now chief chemist of the Union Sugar Company at Betteravia, California, has been appointed field assistant in agricultural extension in the university.

Dr. E. G. Kennard, of Cornell University, has been appointed instructor in physics at the University of Minnesota.

Mr. A. V. HiLl has been appointed to the Humphrey Owen Jones lectureship in physical chemistry, at the University of Cambridge.

\section{DISCUSSION AND CORRESPONDENCE}

GYROSCOPIC QUANTA

IN the note ${ }^{1}$ on gravitationally produced vortices in the ether and their relation to Planck's quantum theory, attention should perhaps have been called to some additional deductions.

For example, that it necessarily follows from the writer's electrostatic-doublet vortex theory of matter, ${ }^{2}$ that the energy radiated when a distortional ether wave strikes an

1 ScIENCE, October 17, 1913.

2 See papers referred to $1889-1900$ in previous note. atom will be given off in quanta and be proportional to the frequency.

The simplest way of seeing this is to take the well-known experiment in which a gyroscope is held in the hand and the body revolved first in one direction and then in the other. On turning the body in one direction no effect is produced on the gyroscope. On turning in the other direction the gyroscope resists and is upset, and the axis then points in the opposite direction.

It may easily be shown that the amount of work done in upsetting the gyroscope varies directly as the angular velocity of rotation of the body, $i$. e., in the case of the atom and ether wave, is directly proportional to the frequency.

It will be seen that this type of atom is somewhat different from any of those heretofore proposed. For example, instead of the electrons being numerically equal to one half the atomic weight the electrons can be numerically equal to the atomic weight, but only one half of them affected by any given ether displacement.

In addition, the stable equilibrium conditions of this type of atom are comparatively simple and the positive nucleus may be made to vanish, $i$. e., can be formed of a number of negative electrons as pointed out in a previous paper.

Rrookline, Mass.,
March 1, 1914

MULTIPLE FACTORS IN HUMAN SKIN COLOR

A RECENT article by E. C. MacDowell ${ }^{1}$ on "Multiple Factors in Mendelian Inheritance" is highly significant in its explanation of cases of apparently "blended" inheritance. The author gives a clear historical summary of experiments made by various investigators, beginning with Nilsson-Ehle's studies on oats and wheat first published in 1909. The original work reported is upon sizes in rabbit hybrids. It is a continuation of Castle's well-

1 Jour. Exper. Zoology, Vol. XVI., No. 2, pp. 177-194, 1914. 
known studies and was carried out with Castle's own material and with his cooperation and help. The experiments now reported show that the Nilsson-Ehle explanation of "blended" inheritance ( $i$. e., two or more nonallelomorphic factors producing phenotypically similar phenomena) may be applied to size differences in hybrid rabbits.

The fact that crosses between negroes and whites give mulattoes has long been pointed to as proof of "blending." But, as is well known, various pigments are here involved, viz., black, red and yellow. Davenport ${ }^{2}$ has shown clearly that the children of two mulatto parents exhibit great variation in color. Occasionally some are light enough to "pass for whites" when away from home. The explanation of this phenomenon, as based on multiple factors, is suggested by Davenport. In the light of MacDowell's own work and the work that he cites there can be little doubt of the correctness of this view. Probably there are separate factors (determiners) for the several pigments and more than one, perhaps many, for the black pigment.

A quotation from MacDowell's paper shows the conclusions drawn from his studies of rabbits. But his statements may be applied to human skin color and, no doubt, to many heritable characters of human beings:

Offspring from crosses between extremes are generally of an intermediate nature. In the following generation new forms appear that are similar to the original parents or even more extreme. The greater number of individuals are intermediate. In certain cases crosses between similar lines, after a first generation like the parents, give a second generation in which a wide range of grades appear. These are the facts definitely ascertained from the work that has been done. .. The interpretation of multiple factors can be applied to all the facts. It goes hand in hand with the mutation and pure-line doctrines of de Vries and Johannsen, and in its breadth of application, and its comprehensive simplicity, this theory, based on the assumption of the segregation of distinct units, is very attractive; by its use as a working hypothesis important facts have been discovered;

2 "Heredity in Relation to Eugenics," pp. 3638, New York, 1911. its acceptance and further development will help to establish a broad and unified system of heredity.

Doubtless many "well-informed" persons still hold to the idea of "blended" inheritance. It is with the hope of calling attention to the Mendelian phenomena involved that this note is submitted. A careful reading of MacDowell's article will clear up many puzzling difficulties for those who are interested in heredity but have not kept up with the literature of the past few years.

Francis Ramaley

UNIVERSTTY OF COLORADO, BOULdER, CoLo.

\section{DIADOPHIS PUNCTATA IN NORTHERN WISCONSIN}

RUthveN ${ }^{1}$ has recorded the occurrence of the ring-necked snake, Diadophis punctata (Linnæus), at Marquette, Michigan, on the strength of specimens having " been taken by Dr. Downing," but later the same authority states: "The Marquette record is particularly open to question and has not been recorded upon the map."2 Not having seen a specimen from Marquette, Ruthven was perfectly justified in making his later statement, in view of the fact that the locality was considerably beyond the known northern geographic range of the species. It may be interesting, however, in this connection to note that on July 5, 1912, I collected a specimen of this species near Rhinelander, Oneida county, Wisconsin, a locality about 120 miles west-southwest of Marquette, Michigan. The snake was found, one and one half hours after sunset, extended full length across the wheel tracks of a sandy road bordering low second-growth woods of Pinus divaricata, Betula papyrifera, Populus tremuloides and Quercus coccinea; in the late twilight the animal was scarcely visible from the wagon in which $I$ was driving. It made no resistance to being captured, was perfectly docile, and soon became tame. It showed a tendency towards positive reaction to contact

1 Ruthven, A. G., 1906, Report Geol. Surv. Michigan for 1905, p. 111.

2 Ruthven, A. G., Thompson, C. and Thompson, H., 1912, "The Herpetology of Michigan," Michigan Geol. and Biol. Surv., publ. 10, p. 107. 